\title{
Consideración lingüística y social de la injuria en el Tesoro de Covarrubias*
}

\author{
Linguistic and social Consideration of insult in the Tesoro by Covarrubias
}

\section{Cristina Tabernero}

Universidad de Navarra-GRISO, Pamplona, España. Correo electrónico: ctabernero@unav.es

\begin{abstract}
Se estudia en estas páginas el concepto de injuria, la presencia de voces injuriosas y su marcación sociolingüística en el Tesoro de Covarrubias. Se analiza en la obra de este autor las menciones referidas a la ofensa, los términos calificados como injuriosos, el tratamiento de las voces que las fuentes del Siglo de Oro ofrecen como lexemas codificados para el insulto y la posible estratificación social de este tipo de vocablos. El resultado muestra el Tesoro como reflejo de la trascendencia social de la ofensa e inicio de una tradición lexicográfica perpetuada hasta el presente, que huye de la representación léxica de la injuria y de los procesos de desemantización de estos términos. Además, se constata que la palabra injuriosa no marca socialmente al emisor, que debe respetar, sin embargo, determinadas condiciones de uso.
\end{abstract}

Palabras clave: injuria, palabras injuriosas, social, Tesoro, lexicografía.

This study aims at the concept of injury, the presence of insulting words and their sociolinguistic labels in the Tesoro of Covarrubias. This paper analyzes the mentions of the offense, the insults and the treatment of the words that the sources of the Golden Age give as coded lexemes to insult, as well as the possible social stratification of such words. The result shows the Tesoro as a reflection of social significance of the offense and the starting work of a lexicographical tradition, continued to the present, that avoids lexical representation of injury and the loss of meaning of these terms. Furthermore, this dictionary proves that injurious words do not distinguish speakers socially; they must, however, respect some conditions of use.

Key words: injury, injurious words, social, Tesoro, lexicography.

\section{INTRODUCCIÓN}

Estudios diversos sobre la injuria en distintas tipologías textuales, desde la producción literaria del Siglo de Oro, pasando por causas inquisitoriales o procesos legales, hasta escritos más prosaicos y cotidianos como los pintados en paredes,

Este artículo forma parte de los resultados del proyecto HAR2012-31536, Discurso y poder, lengua y autoridad en el mundo hispánico (siglos XVI-XVII), subvencionado por el Ministerio de Economía y Competitividad (España). 
han mostrado sobradamente el importante papel que el insulto ${ }^{1}$ desempeñaba en la sociedad aurisecular (Pérez-Salazar, Tabernero y Usunáriz 2013) en su función de elemento de descrédito ${ }^{2} \mathrm{y}$, por tanto, constituyente de lo que la pragmática denomina agresión o descortesía verbal. ${ }^{3}$ Dicho de otro modo, el insulto o la injuria se definen unánimemente como actos de habla que no tienen razón de ser fuera del proceso comunicativo, dado que se realizan únicamente en el momento en que se consigue la ofensa al interlocutor. Ahora bien, resulta igualmente indudable que la lengua posee ya lexicalizada y codificada una serie de voces y expresiones que se emplean como insultos, al menos en alguna de sus acepciones. Por esta razón, aun de acuerdo con las palabras de F. Lara que recoge M. Colín (Lara 1998, apud Colín 2003: 113), según las cuales "todo puede ser un insulto menos su definición", la información lexicográfica, sobre todo en épocas pasadas, se convierte en fuente de consulta inexcusable, principalmente cuando se trata de obras que, aún lejos de la lexicografía moderna, proporcionan marcas de uso sobre los términos que lematizan.

Si hablamos de Siglo de Oro, de diccionario y de información sociolingüística y estilística, las miradas han de apuntar casi con seguridad al estudio del Tesoro de Covarrubias, que ha recibido ya merecida atención en este sentido. ${ }^{4}$ No han sido pocos los estudiosos que se han referido a la información pragmática que el toledano proporciona en su obra, ensalzando sus contornos de definición. E. Ridruejo, por ejemplo, resalta la dificultad que se impone a una lexicografía que, bilingüe hasta aquel momento, debe transmitir aspectos de uso y variaciones de significado provocadas por las circunstancias de enunciación, cuyo reflejo se considera hoy obligado. Partiendo de esta misma necesidad, en los inicios de una lexicografía monolingüe carente de modelos, Covarrubias "incluye en sus definiciones los entornos o situaciones en que se presentan determinados mensajes lingüísticos, los protagonistas que pueden emitirlos e incluso la intencionalidad que los hace posibles" (Ridruejo 2000: 137).

Resultan casi inexistentes, sin embargo, las referencias a la consideración que el toledano descubre a través de su obra en torno a la afrenta como elemento de uso común en la lengua de los siglos XVI y XVII. En el marco más amplio de un estudio sobre la injuria en la época aurisecular, las páginas de este trabajo persiguen un doble objetivo: el análisis de uno de los aspectos desatendidos hasta el momento en el

Cabe emplear insulto e injuria como términos sinónimos, si bien podrían establecerse entre ellos distinciones de matiz: usos diacrónicamente diferentes en la medida en que el segundo predomina en el español medieval y moderno, tal vez por una mayor dependencia de la tradición del discurso jurídico, al que hoy se vincula injuria, frente al más general insulto. Esta misma descripción y pertenencia a un lenguaje especializado marca, en cierto modo, una distinción que puede ser al mismo tiempo estilística y social.

2 De este modo se observa, por ejemplo, su empleo en la estigmatización de los conversos (cf. Usunáriz 2013). Para el insulto como estrategia de descrédito en la sociedad actual, cf. López Martín (2013).

3 Resulta ya lugar común en los estudios sincrónicos y diacrónicos sobre insultos e injurias (cf., entre otros, Castillo 2004; Colín 2003; Herrero 2007 y 2013; García-Medall 2008; Tabernero 2010 y 2013; López Martín 2013) su descripción como elementos que contravienen las normas de cortesía (cf. Austin 1994), en cuanto suponen una ofensa para el interlocutor, y la referencia a su carácter de acto ilocutivo expresivo, que busca crear un perjuicio en el oyente (cf. Haverkate 1994).

4 La mayoría de los autores que ha analizado la obra de Covarrubias ha destacado su valor como fuente de información para el conocimiento de la lengua y sociedad del Siglo de Oro. Cf., por ejemplo, Salvador (1988), o el prólogo de D. Reyre (2006), a una de las ediciones del Tesoro; además, son varios también los estudios que se han preocupado por las marcas de uso en este diccionario, a veces en el marco de análisis más amplios, entre los que cabe citar a Gemmingen (1992), Garriga (1997), Ridruejo (2000), Seco (2003a) y Azorín (2000). 
Tesoro y la información sobre el uso del insulto desde la perspectiva lexicográfica. De acuerdo con esta finalidad, examino en las páginas que siguen la consideración de la injuria en Covarrubias a través de las menciones que a este respecto aparecen en su obra; el tratamiento en su diccionario, en comparación con la lexicografía académica primera-Autoridades-, de aquellos términos que los textos presentan codificados en el uso de la sociedad contemporánea y su posible estratificación sociolingüística de acuerdo con las opiniones diseminadas en el Tesoro.

\section{Concepto de injuria en el Tesoro}

El concepto que Covarrubias posee de afrenta o injuria y la importancia que le concede en su obra coincide con el de una sociedad que se rige por valores como el deshonor y la ofensa, que solo se consuman y son, por tanto, sancionables, en razón de su publicidad (cf. Tabernero 2010 y 2013). Es decir, en el caso de la ofensa, del agravio, de la injuria, la herida fundamental no consiste en el acto de pronunciar una determinada palabra, ni siquiera en la verdad o falsedad que aquella presenta en relación con el referente que el ofensor le atribuye; antes bien, es la "in-famia", la imagen pública perjudicada, el honor dañado, en definitiva, la acción constitutiva de delito, y así lo aclara Covarrubias en la definición de afrenta (s.v.): "Es el acto que se comete contra alguno en deshonor suyo, aunque sea hecho con razón y justicia, como azotar a uno o sacarle a la vergüenza. [...] También se recibe afrenta de palabra, como si a uno le dijesen ladrón, o otra palabra de las injuriosas", o en la entrada baldón: "Palabra antigua castellana; vale denuesto o palabra afrentosa con que damos en rostro al que menospreciamos y tenemos en poco" (s.v.). Además, la injuria verbal supone una pérdida de respeto hacia el otro en los casos en que aquel es debido: "Decirle a uno en sus barbas algún denuesto es haberle perdido el respeto, quien debía tenérsele y reverenciarle” (s.v. barba).

\subsection{La injuria no verbal}

El análisis de las menciones que se leen en el Tesoro de términos relacionados con el agravio o la afrenta comprueba la relevancia social que el autor atribuye a la injuria. Covarrubias dispersa por su obra un buen número de voces -afrenta, afrentar, afrentoso, agraviar, agravio, contumelioso, escarnio, denostar, denuesto, improperio, infamar, infame, infamia, injuria, injurioso, insultar, insulto, menosprecio, vituperio, vituperar, vituperoso- para referirse en su mayor parte a acciones, ${ }^{5}$ sobre todo cuando aquellas aparecen como exégesis de antropónimos, topónimos y gentilicios ${ }^{6}$ o en las fábulas, cuentecillos y pequeñas historias que a menudo ilustran las entradas -desprecio, elefante, cabello-; con frecuencia estas alusiones forman parte de la definición -agraviado (s.v. agravio), desafuero (s.v. fuero), deshonra, guardar,

Los estudios sobre el insulto han convenido en su carácter de acción verbal y no verbal, es decir, que el insulto puede entenderse principalmente en dos sentidos, a saber: como acción y como palabra (Colín 2003: 149). De hecho, el insulto se ha reconocido como un fenómeno de múltiples implicaciones y de un alcance más amplio que el meramente lingüístico al afectar a cuestiones sociales -socialización, violencia, agresión, cortesía- y cognitivas.

6 Se constata así en las voces Alcipo, Alfonso, Antíopa, Ceres, Clelia, Cid, Critis, Dido, Filomela, Himeneo, Menelao, Craso, Creonte, Egles, Elena, Filipe, Medea, Medusa, Lisímaco, Lucrecia, Cartuja, Huelgas, Vera, argipeos. 
infamar (s.v. infame), jugar de antuvión, ${ }^{7}$ padecer, perdonar, queja, vengar-, de los sinónimos que definen -contumelia, denostar, ${ }^{8}$ denuesto, desaguisado, demasía, injuria, ignominia, ignominioso (s.v. ignominia), injuriado (s.v. injuria), injuriar (s.v. injuria), injusto, mengua, tuerto- o surgen al hilo de la explicación etimológica (enojar). Estos últimos casos conforman los términos que en el Siglo de Oro se incluyen en el campo asociativo ‘injuria' o 'afrenta' según la información que podemos extraer del Tesoro.

Por otra parte, se mencionan explícitamente gestos de significado injurioso según las convenciones sociales del momento: tirar un cohombro mojado o lleno de sangre (s.v. infante), asir a un hombre de la barba, pelarle las barbas o cortárselas (s.v. barba), escupir a otro en la cara (s.v. escupir), dar a uno con vaina (s.v. vaina), desceñir a alguien (s.v. desceñir), dar o recibir una bofetada (s.v. bofetón), cortar las faldas (s.v. falda), dar un alpargatazo (s.v. alpargate), golpear en la cara a mano abierta (s.v. puño), dar con un buétago de vaca por la cara (s.v. buétagos), hacer la mamona (s.v. mamón); se anotan también signos de afrenta: la argolla de los esclavos (s.v. argolla), la coroza (s.v. encorozar), el saco de los penitentes (s.v. San Benito), los palos con que se disfrazaba a los esclavos (s.v. horca), los cabellos cortados (s.v. cabello), el trasquilado a cruces (s.v. tresquilar), la acción de salir montado al revés en un caballo, con la cola en la mano (s.v. cola), la chía colorada de las mancebas de clérigo (s.v. mancebo), las marcas de tinta o almagre en la puerta (s.v. almagre).

Por el Tesoro sabemos igualmente que la agresión de injurias estaba penada con una sanción económica, que afectaba también a los hidalgos, siempre que mediara una denuncia ante el juez y este dictara sentencia: "Para lo cual es de saber que cuando un hidalgo recebía agravio de algún otro, podía vengar, conviene a saber, recebir de su adversario por condenación de juez competente, en satisfación de su injuria, quinientos sueldos" (s.v. fidalgo).

\subsection{La injuria verbal}

En contraste con la situación examinada respecto a las menciones sobre el hecho injurioso, no suponen demasiados los casos en que se explicita la injuria o la afrenta como producto de la palabra emitida en un acto de habla. Pueden contarse entre ellos la voz gafo, que, según Covarrubias, representa mayor grado de afrenta que leproso ("era notable afrenta la que se hacía a uno en llamarle leproso y particularmente gafo", s.v.). En esta ocasión Covarrubias hace referencia al Viejo Testamento ${ }^{9}$ y a las

"Jugar de antuvión, es adelantarse y ganar por la mano al que viene a hacer algún desaguisado o agravio", s.v. antuviar

8 Denostar y denuesto aparecen definidos sinonímicamente bajo el lema honesto, aunque denostar cuenta también con entrada propia.

9 “En el Testamento Viejo era notable afrenta la que se hacía a uno en llamarle leproso y particularmente gafo, y por tal la tuvo el rey David cuando, a la hora de su muerte [...] encargó a su hijo Salomón tomase venganza de Semeí, el cual al tiempo que iba huyendo de Absalón le iba denostando y afrentando" (s.v. gafo). 
leyes recogidas en la Nueva Recopilación, que castigan, por delito de injurias, ${ }^{10}$ los términos gafo, sodomético, cornudo, traidor, hereje y puta. ${ }^{11}$

Otra de las escasas referencias explícitas al carácter injurioso de las palabras viene representada por el sustantivo bigardo, propio, como señala el autor, de la "gente mal considerada" ("Término injurioso, del cual la gente mal considerada suele usar cuando trata con irreverencia a algún religioso, y no saben lo que se dicen, ni lo consideran", s.v.); el toledano arremete con especial vehemencia contra el uso de este término, según muestra la reiteración en vigardo ("este término injurioso y escandaloso, de que la gente mal considerada suele usar cuando trata el religioso con poca reverencia y respeto, a mi parecer sinifica más de lo que el vulgo piensa, porque bigardo es vocablo corrompido de begardo", s.v.). En esta insistencia asoma, como resulta fácilmente deducible, la implicación personal de su condición religiosa.

Anota también Covarrubias como expresiones afrentosas sois un figón, que señala a quienes practican la sodomía, ${ }^{12}$ [mandar a alguien] al rollo de Écija, que le estire (s.v. Écija), usado entre "gente pícara" para "despedir a uno con desgaire y menosprecio", o traer rotos los carcañales, dirigido a a una mujer deshonesta. ${ }^{13}$ Igualmente injurioso resulta, al decir de Covarrubias, el término cesto empleado como ofensa hacia otro para referirse a su incapacidad, ${ }^{14}$ furcifer, "nombre afrentoso" (s.v. horca), o ladrón y cornudo ("También se recibe afrenta de palabra, como si a uno le dijesen ladrón, o otra palabra de las injuriosas", ${ }^{15}$, s.v. afrenta, "Palabras mayores, ${ }^{16}$ son las injuriosas, como ladrón, cornudo, etc.). Se incluyen asimismo en esta lista las denominaciones de menosprecio como fulanillo y zutanillo ("Fulanillo y zutanillo por menosprecio, no dignándonos de señalarlos por sus nombres, y así vale tanto como gente ruin, de la cual se hace poco caso", s.v. fulano) o los usos de tuerto

10 "Qvalquier que à otro denostare, y le dixere gafo, o sodometico, o cornudo, o traydor, o hereje, o à muger que tenga marido puta, o otros denuestos semejantes, desdigalo ante el Alcalde, y ante hombres buenos al plaço que el Alcalde le pusiere: $\mathrm{y}$ peche trecientos sueldos; y por ellos mil y docientos marauedis: la mitad para nuestra camara, y la otra mitad para el querelloso: y si fuere hijodalgo el que dixere los dichos denuestos, no sea condenado à que se desdiga por ello, y pague quinientos sueldos, y por ellos dos mil marauedis: la mitad para nuestra Camara, y la mitad para el querelloso y demas desto el Iuez le ponga la mas pena que le pareciere, segun la calidad de las personas, y de las palabras. Y si hombre de otra ley se tornare Christiano, y alguno le llamare tornadizo, o marrano, o otras palabras semejantes, peche diez mil marauedis para nuestra Camara, y otros tantos al querelloso" (Nueva Recopilación, 1567, libro 8, tít. 10, ley 2). Como es sabido, el castigo por delito de injuria está presente desde la tradición jurídica medieval. Cf. para el papel de la injuria en los textos legales de la Edad Media, Madero (1992) y para el análisis lingüístico de la injuria en los fueros medievales, Castillo (2004) y para el papel social de la injuria en la sociedad bajomedieval, Segura (2005).

11 Como veremos, Covarrubias solo señala la injuria en el caso de gafo y cornudo; no se hace mención alguna sobre este hecho en el resto.

12 “De lo dicho se entenderá lo que sinificará esta palabra figón, cuando por afrenta dicen a uno: «Sois un figón»” (s.v. higo).

13 "Se dice por afrenta a la mujer deshonesta, por lo que huella con ellos", s.v. carcañal.

14 "Por afrenta se dice a uno que es un cesto, por cuanto está vacío del licor de sabiduría y discreción, como hombre incapaz, que lo que oye le entra por un oído y se le sale por el otro, como acontecería si uno quisiese echar agua en cesto, que se toma por cosa perdida y sin provecho", s.v. cesto.

15 Se refiere Covarrubias a las enumeradas en la Nueva Recopilación.

16 La legislación de la España medieval y moderna distinguía entre palabras mayores -las seis mencionadas anteriormente- y menores, de acuerdo con el grado de delito; se penaban, por tanto, con sanciones pecuniarias diferentes (cf. Nueva Recopilación, libro octavo, tít. X, ley iii). 
y cojo, dirigidos como burla y escarnio a quienes sufren estas limitaciones, ${ }^{17}$ de igual modo que sucede con destripaterrones aplicado al labrador. ${ }^{18}$

\section{Voces inJuRIOSAS EN EL TESORO}

\subsection{Datos cuantitativos y cualitativos}

A partir del análisis en el Tesoro de los términos que en el Siglo de Oro integran el campo asociativo de la 'afrenta', revelados por el propio Covarrubias (cf. supra), se ha obtenido el reflejo que la obra del toledano devuelve sobre la consideración de la injuria, sea esta acción o palabra; sin embargo, para completar este estudio se impone ahora el análisis de los términos que en la sociedad áurea se empleaban como insultos, según lo prueban fehacientemente las voces atestiguadas en procesos judiciales de aquella época; ${ }^{19}$ es decir, se trata de comprobar en qué medida la obra examinada representa un retrato íntegro de la lengua de su tiempo.

Así pues, considero en esta ocasión la presencia o ausencia en Covarrubias de 165 voces $^{20}$ injuriosas, las que ha arrojado hasta el momento el expurgo de los anteriormente mencionados procesos por injurias, de las que el Tesoro incluye, ya sea como entrada independiente o inserta de diferentes maneras en el cuerpo de otra, cuarenta y tres, lo que supone un porcentaje $(26,06 \%)$ no muy representativo respecto al total, aunque tampoco desdeñable.

De acuerdo con la clasificación de estos términos expuesta en un trabajo anterior (cf. Tabernero 2013), que distinguía entre características extrínsecas -condición moral ('vileza'), privación de cualidad, privación del sentido o de la inteligencia, vicios, comportamiento sexual, condición física (y moral), condición heredada, condición religiosa- e intrínsecas al individuo -extracción social, procedencia geográfica-, casi la totalidad pertenece a los términos que refieren rasgos intrínsecos, distribución evidente, en cierto modo, por el mayor número de categorías que se agrupan bajo esta etiqueta frente a solo dos extrínsecas. Covarrubias dedica espacio en su Tesoro a la condición religiosa -judío, judigüelo, marrano-, a los vicios -borracho, cuero de vino, ladrón, rapaz, robador-, a la condición moral denostable-alevoso, chocarrero, ganapán, logrero, rebolbedor, rufián, villano-, a la privación de inteligencia asno, loco, necio, majadero-, a la privación de cualidad-aborrecido, apasionado, desbenturado, parlero, perjuro, tacaño-, al comportamiento sexual -bagasa, cachonda, cornudo, mala embra, puta, raposa-, a la condición heredada -borde-, a

\footnotetext{
"Decís a uno tuerto o cojo y contrahaceisle por menosprecio y burla. Esto es hacer escarnio, y hanse visto castigos notables, que Dios ha hecho en gente escarnecedora y burladora de los pobres lastimados", s.v. escanecer).

“Agora, por escarnio, llamamos destripaterrones al labrador" (s.v. Agricultura).

19 En trabajos anteriores se ha procedido al estudio detallado de algunas de estas voces (cf. Tabernero 2012) y a la delimitación de los campos nocionales en los que se incluyen (Tabernero 2013).

Se trata de un corpus sobre el que he trabajado ya en ocasiones anteriores constituido por procesos por injurias de los siglos XVI y XVII en los que se tiene acceso a los términos injuriosos, a los protagonistas de la injuria -injuriador e injuriado- y a variables que constituyen el perfil de aquellos -sexo, oficio. El número de voces que señalo puede verse modificado en virtud de algunas consideraciones en el cómputo como la separación en términos distintos según la categoría gramatical de una misma voz (p.ej., puta) o el recuento únicamente por vocablos aislados o en compañía de otros (ladrona/ ladrona probada y açotada). En cualquier caso, la nómina sigue ampliándose con la revisión de nuevos procesos.
} 
la condición física (o moral) -buoso, çafio, cagón, cochino, hediondo, gorda, tiñoso, tocino, tuerto-, entre los intrínsecos, y al oficio como signo de extracción social vituperable-lacayo, lavandera-, entre los extrínsecos.

Fig. 1. Distribución de términos injuriosos en Covarrubias

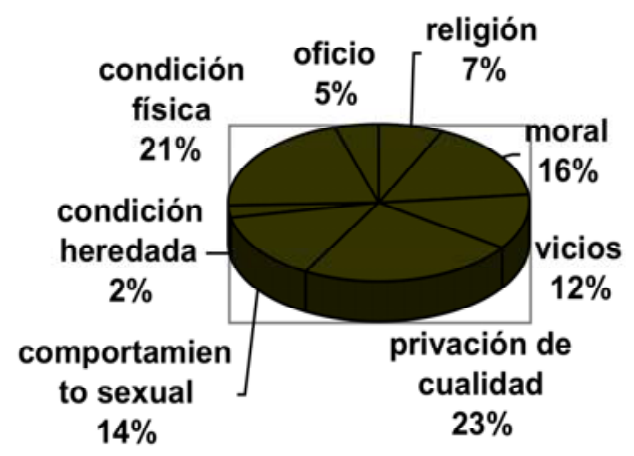

Según se aprecia en la Figura 1, apenas existen diferencias significativas entre los grupos de términos referidos a la condición física, al comportamiento sexual, a la condición moral, a la privación de cualidad o a los vicios, mientras que descienden gradualmente los propios de la privación de inteligencia, de la condición religiosa, de la heredada y del oficio.

Llama la atención, sin embargo, la circunstancia de que son casi inexistentes las referencias a la condición injuriosa del término en aquellos casos en que las fuentes del Siglo de Oro prueban la cotidianidad de su uso: entre los especialmente característicos de la época, a cuya difusión ha contribuido en buena medida la producción literaria del momento, se encuentran borracho y rufián, que no recogen Covarrubias ni la lexicografía inmediatamente posterior; en el caso de rufián, Autoridades, en contraste con los innumerables testimonios de la documentación áurea (cf. Tabernero 2012, 502-505), no se hará eco de su empleo como voz vituperosa, vacía del significado recto, hasta la edición de 1852. Otros denuestos, comunes en los escritos áureos, a los que el toledano se refiere igualmente sin mención alguna de su empleo injurioso, son aborrecido, amancebado, alevoso, apocado, borde, buboso, cagón, cantonera, cochino, desventurado, (puta) escaldada, ganapán, gordo, hediondo ${ }^{21}$, lacayo, lavandera, loco, logrero, majadero, marrano, revolvedor, robador, tacaño, tiñoso, tuerto, zafio; las obras diccionarísticas publicadas tras el Tesoro comparten en el caso concreto de estas voces la práctica según la cual se ofrece únicamente la definición sin marca de uso (cf. Nuevo Tesoro Lexicográfico de la Lengua española [NTLLE] s.vv.).

\subsection{Acepciones discrepantes}

Ahora bien, no coincide en algunos de estos casos la definición lexicográfica del Tesoro, a veces incluso ni siquiera la de otras obras lexicográficas, con los significados que, de acuerdo con los testimonios escritos, debían estar ya extendidos en el uso

Entre Covarrubias y Autoridades, hediondo registra cambios de significado: para la Academia, al aspecto puramente higiénico, ha de sumarse la acepción metafórica ‘hombre enfadoso, mal sufrido e impertinente’ (s.v.). 
común de los hablantes de los siglos XVI y XVII. Así, por ejemplo, cagón, 'hombre de poco ánimo’ para Covarrubias y Autoridades, apunta en la documentación hacia un sinónimo de bellaco, al igual que cochino: "Don bellaco, cagón ¿y aún no teneys enpacho de llegar a la puerta de nuestra casa?" (1537); ${ }^{22}$ "un bellaco, cochino y que me había ydo a Çaragoça fuyendo por deudas" (1539); tiñoso -“que aunque me pesasse de la varba que los echarían y que era un tinoso, vellaco, ruyn que estasse en noramala" (1541)-, que no se refiere al aspecto físico sino al rechazo que esta característica produce por el valor social que se le atribuye, siendo esta circunstancia la que traslada el significado del término hacia su connotación ('malo'), de referentes mucho más amplios. Lo mismo que sucede con ganapán (var. galapán) -“lebantó el braço para asirme de mi dicha barba y lo ubiera efectuado si no le estorbara quanto más que me llamó bellaquo, galapán y que ella era muger de mejor hombre que yo" (1548)-, que retratado por Covarrubias y Autoridades como el hombre honrado que sufre y trabaja para conseguir su sustento, se entiende y usa comúnmente por el desharrapado, fuera del orden establecido y, en consecuencia, 'malo'. También se comprueba este proceso en chocarrero ${ }^{23}$, que es, según el Tesoro,

el hombre gracioso, y truhan, quasi iocarrero, a ioco, porque es hombre de burlas, y con quien todos se burlan; y tambien se burla el de todos, porque con aquella vida tienen libertad, y comen, y beuen, y juegan; y a vezes medran mas con los señores que los hombres honrados, y virtuosos, y personas de letras. Dizen que los palacios de los Principes no pueden passar sin ellos (s.v.).

En esta definición, sin hacerse referencia explícita al carácter negativo del término, se apuntan algunas notas que dejan entrever la valoración del propio autor, basadas, según parece, en constataciones sociales. Como ofensa, sin embargo, la lengua común emplea ya en el siglo XVI chocarrero como 'mala persona, de mal comportamiento', en el mismo sentido que bellaco, de acuerdo con el testimonio que se recoge en los procesos de injurias -"que hera un gran vellaco, choquarrero, que andaba con mugeres agenas y que hera tan bueno como él" (1533) - o rufián -“llamó al dicho Johanco rufián y chocarrero" (1529)-. Será a partir de su relación metonímica con otros calificadores negativos, con los que habitualmente se relaciona, como la lengua común puede despojarlo de su sentido primero y generalizarlo en el más amplio de ‘bellaco' o ‘malo'. ${ }^{24}$

Tampoco en tocino ("Sallí acá, don puerco, vos me abeys de prender, que soys un tocino", 1542) y raposa ${ }^{25}$ ("Raposa, raposa. Los raposos los perros suelen comer

22 En el caso de los testimonios del corpus señalo únicamente la fecha del proceso.

23 Las concordancias de este término, al menos las comprobadas en CORDE, corresponden mayoritariamente a los siglos XVI y XVII, en tanto que solo un testimonio se sitúa en el siglo XV, en el sentido posiblemente de 'charlatán' o tal vez de ‘bellaco’ (CORDE [consulta 16-03-2013]).

El examen de testimonios del CORDE y de otras fuentes consultadas arroja los siguientes resultados sobre el uso de chocarrero: en los testimonios del siglo XVII y en los escasos recogidos en el XVIII el significado se asocia siempre con la palabra y la burla para llegar al XIX relacionado con lo grosero y grotesco. La revisión diacrónica a través de los datos del CORDE ofrece una figura muy asentada en la corte del siglo XVI, que se reduce en el XVII y que continúa en declive durante las centurias siguientes. De este modo, los 89 documentos (135 ocurrencias) se reparten como sigue: uno del siglo XV, 33 del XVI, 15 del XVII, 8 del XVIII, 9 del XIX y 20 del XX. [Consulta 18-03-2013] 
y a ti también los perros te han de comer", 1538) Covarrubias -ni Autoridades más adelante- apuntan los significados figurados. El zafio, que se define por ser "villano descortés y mal mirado" (Covarrubias, s.v.) y "tosco, inculto, ignorante,o falto de doctrina" (Autoridades, s.v.), pierde en el uso injurioso rasgos sémicos en la medida en que todos ellos representan la generalidad de 'lo malo' -“don vellaco, çafio, de mejor hombre y de más honrado que de vos tube la creatura, que es un escribano y que ella para muger hera más honrada que él para hombre" (1549).

Posiblemente, el caso más llamativo sea el de puta que, a pesar de su codificación probada como insulto desde la Edad Media, en uso adjetivo o sustantivo, no se presenta de este modo en las fuentes lexicográficas hasta la edición académica de $1984^{26}$ ("Dícese como calificación denigratoria, aunque por antífrasis puede resultar encarecedor", s.v.); esta afirmación incluye, claro está, el Tesoro de Covarrubias, a pesar de que la legislación medieval recoge el término como palabra injuriosa en su sentido recto (cf. Madero 1992 y Castillo 2004). Ahora bien, la transcategorización gramatical de esta voz, que en estos siglos se emplea también en función adjetiva -lo mismo en femenino que en masculino-, adelanta respecto a la consideración lexicográfica su desviación significativa hacia un sentido más amplio que, si bien conserva en múltiples ocasiones reminiscencias del originario, pasa en otras a una designación más imprecisa ('mala mujer', 'malo, -la'), como esta del año 1536 en la declaración de la costurera María de Urriza, extraída de los testimonios de nuestro corpus, donde el insulto pierde su significado primigenio: "Y a esto la dicha acusada dixo que me daría con un aspa que llebaba en las manos una buena señal en la cara y porque yo le respondí "vos hareys menos", començó la dicha acusada a dezir y me dixo de puta açotada, corrida, linpiada".

\subsection{De Covarrubias a Autoridades}

En otros casos, los testimonios presentan variaciones de significado que, si bien ausentes del Tesoro, y también de Autoridades, ofrecen en este último acepciones figuradas aproximadas a aquellas. Por ejemplo, loco encuentra en la definición de Autoridades, esto es, "sugeto de poco juicio y asiento, disparatado e imprudente" (s.v.), el significado que lo acerca al más amplio, común en los textos de la época: "Y ella le respondió que fuesse a casa, deziéndole loco, bellaco [traydor] que ya es tarde y que la arma de la muger no hera sino una rueca y que sabeys que no soy hombre que si fuera hombre, de los ojos colorados no me hobieras afrontado dessa manera" (1538); "que hera un loco, perro salbaje, suzio" (1543).

Sucede de este modo también con rapaz, que en el sentido de 'malo', constante en los testimonios de los procesos ${ }^{27}$ no se registra en la lexicografía, aunque Autoridades apunta una acepción que permite intuir la más general: "El que tiene inclinacion o está enviciado en el robo, hurto o rapiña", s.v.; lo mismo que en lechón ("Por semejanza se llama el hombre demasiadamente suzio y desaseado en el vestir o en el comer",

26 Anteriormente Domínguez incluye en su obra la entrada puto, ta. con el significado 'putesco' (ant.). Cf. para ambos, NTLLE, s.v. puto.

27 "Don rapaz, vellaco, yo os cargaré de coçes como a un rapaz y a otros mejores que a vos he dado de coçes, don ruyn mulatero y azeitero que vos soys" (1536); "que él nunca tal dixo como en la respuesta se dezía y que como vellaco, falso y mentiroso puse y scriuí una cosa por otra, amenazándome que yo vuscaua el cinque pie del carnero, siendo presente yo y deziendome que fuese de donde él estaua, sino que votando a Dios y llamándome rapaz, villano que si él me tomaua me sacudiría" (1534). 
DA, s.v.) o villano. A propósito de este último Covarrubias destaca únicamente su condición "rústica y desapacible" (s.v.), que se contrapone al empleo lexicalizado, de amplia documentación en el siglo XVI, en el sentido que pasa a señalar Autoridades en el XVIII ("Significa tambien ruin, indigno, u indecoroso", s.v.), mucho después de que se hubiera asentado en el uso el carácter infamante del término, que al menos desde la Baja Edad Media, y más propiamente a partir de la centuria del quinientos, ha perdido su valor social (cf. Segura 2006: 167-168).

Por otro lado, el Diccionario de Autoridades anota en algunas voces de las coincidentes con Covarrubias, escasas, la marcación de uso injurioso que lo separa del Tesoro: en bagasa -"Nombre injurioso que se daba a las mujeres perdidas" (Autoridades, s.v.)-; en judío -"Voz de desprecio y injuriosa, que se usa en casos de enojo o ira: y tambien para notar a alguno de que tiene raza o executa cosa que parece que da a entender que la tiene", Autoridades, s.v., acep. $3^{28}$ - y judihuelo (var. judigüelo) -“Ahora se usa y se dice por desprecio de cualquier judío, o que tiene sospecha de serlo" (Autoridades, s.v. judío)-; en desventurado -“por modo de desprecio" (Autoridades, s.v.)- y majadero -"Se dice hoy por injuria al hombre necio, pesado y porfiado" (Autoridades, s.v.)-, ${ }^{29}$ ampliamente atestiguadas todas ellas entre la nómina de términos vituperosos de aquellos siglos. ${ }^{30}$

Por el contrario, de acuerdo con los resultados del análisis realizado en el epígrafe anterior, apenas pueden contarse las voces que presentan en el Tesoro indicaciones sobre su uso injurioso: tan solo cornudo, ladrón y mala hembra componen la nómina aludida. A cornudo se refiere Covarrubias como "una de las cinco palabras injuriosas, que obligan a desdecirse dellas en común, fuera los que excepta la ley" (s.v.), siendo así que puta, cuya condición injuriosa ni se menciona (cf. supra), es otra de las que recoge la recopilación legal. ${ }^{31}$ En este caso, por contraposición a la tendencia señalada anteriormente, Autoridades no señala la utilización vituperosa del término, del que apunta únicamente el proceso metafórico que da lugar a la designación del 'hombre al que su mujer engaña', significado que, según ratifican los testimonios textuales y la lexicografía, no parece desvincularse en ningún caso del metafórico primero.

Por su parte, ladrón se anota como voz afrentosa ("También se recibe afrenta de palabra, como si a uno le dijesen ladrón, o otra palabra de las injuriosas", s.v. afrenta), no separada apenas del significado recto. En mala hembra, que a menudo se emplea en los textos como sinónimo de puta (cf. Herrero 2007: 361, y Tabernero 2013: 267-268), reconoce el toledano la afrenta con marcada expresividad: "Mala hembra, es todo quanto malo se puede dezir, y en fin nacimos de hembras, y sea hi de mala el que dixere de proposito mal dellas", s.v. hembra.

\footnotetext{
28 Domínguez, en la línea valorativa común a su diccionario, recoge la siguiente acepción para judío: “fam. Voz injuriosa, depresiva, despreciativa que se suelta como epíteto infamante en momentos de cólera y enojo, denostando a cualquier individuo por mal cristiano, ruin, miserable o cosa parecida; ni más ni menos que por costumbre análoga y en alusiones soberanamente necias, se suele decir: perro, turco, moro, hereje, y otras lindezas" (NTLLE, s.v.).

29 En majadero Covarrubias ofrece la acepción figurada: "Llamamos majadero al necio, por ser boto de ingenio, como lo es la mano del mortero, a que se hace alusión”, s.v. majar.

30 Cf., por ejemplo, para bagasa, en su uso literario, Herrero (2007: 361), y para el empleo de judío en la documentación del Siglo de Oro, Usunáriz (2013).

31 Cf. notas 11 y 17.
} 
Comparando estos datos con los que ofrece la obra de inicio de la labor lexicográfica de la Academia (fig. 2), su Diccionario de Autoridades, comprobamos que de las 165 voces constatadas como injurias en el corpus se registran en Autoridades ochenta y cinco (51,51\%), lo que supone una diferencia respecto a Covarrubias de un 25,45\% (cf. §2.1).

Fig. 2. Voces injuriosas en Covarrubias y Autoridades

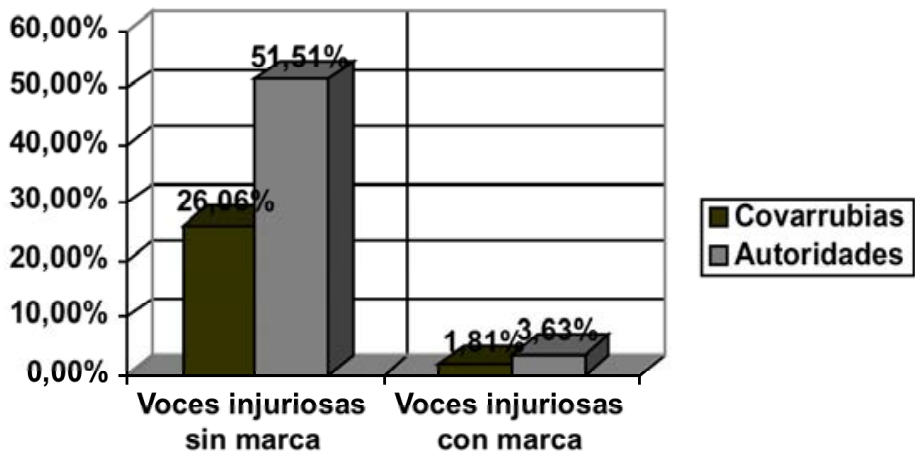

A estas proporciones ha de añadirse otra consideración (Fig. 2), que altera los datos puramente cuantitativos, a saber: la Academia en casi la totalidad de estas ochenta y cinco voces, coincidentes unas sí y otras no con Covarrubias, presenta la acepción figurada en la que el término puede emplearse de forma insultante; por el contrario, son proporcionalmente poco representativos los casos en que se marcan explícitamente estos términos como afrentosos: ${ }^{32}$ a bagasa, desventurado, judío y majadero, señalados más arriba en el grupo de términos del corpus que Covarrubias y Autoridades incluyen en sus obras, han de añadirse perro ("Metaphoricamente se da este nombre por ignominia, afrenta y desprecio, especialmente a los moros o judios", s.v.), cagado ("Se llama por desprecio metaphoricamente al hombre que es para poco y sin espiritu", s.v.) y gabacho ("Es voz de desprecio con que se moteja a los naturales de los pueblos que están a las faldas de los Pirineos entre el río llamado Gaba, porque en ciertos tiempos del año vienen al Reino de Aragón y otras partes, donde se ocupan y exercitan los ministerios mas baxos y humildes", s.v.).

\section{Marcaciones diastráticas en el Tesoro}

Según el método propuesto en las primeras páginas de este trabajo, queda por comprobar la adscripción sociolingüística que el Tesoro concede al uso de voces injuriosas. Parece adecuado este análisis en los tratadistas de una época, y Covarrubias es considerado entre ellos, en que son frecuentes las referencias a niveles de habla en

En el caso de hi de puta, Autoridades incluye la siguiente valoración en hijo de su madre: "expresión que se usa con alguna viveza para llamar a alguno bastardo, o hijo de puta", mientras que en hijo de puta se ofrece únicamente el significado 'el que no es procreado de legítimo matrimonio' (DA, s.vv.). La voz aporrado aparece marcada como "término baxo y vulgar" pero sin referencia al carácter injurioso. 
función de claras divisiones sociales. ${ }^{33}$ De hecho, la bibliografía sobre el Tesoro ha destacado la información que al propósito mencionado ofrece su autor, ${ }^{34}$ de manera que se puede constatar la presencia de voces de la lengua culta al lado de las que el toledano considera propias de otro nivel que, según uso de la época ${ }^{35}$, ha de denominarse, por ejemplo, rústico, grosero o aldeano, de cuyos individuos representativos hallamos rasgos dispersos por las páginas del Tesoro (Cf. Gemmingen 1992: 27-28 y Azorín 2000: 122). Es el rústico, según Covarrubias, hombre simple y de poco entendimiento, tonto: "con el rústico no se han de usar términos muy cortesanos ni agudos, sino tratarle caseramente" (s.v. conejo), hombre rústico y de poco entendimiento (s.v. tronco), "por ser rústicos, suelen decir algunas simplicidades en lo que proveen, de que tomaron nombre alcaldadas" (s.v. alcalde), "Los que dan unos pasos atrabancados, arrojando tras el pie todo el cuerpo, son rústicos y tontos" (s.v. carcañal), "Porro, decimos al necio por no ser nada agudo, sino grosero" (s.v. porra), "Páparo. El aldeano simple, que viniendo a la ciudad está maravillado y abobado de lo que ve en ella” (s.v.). Es el rústico, además, tosco o grosero ${ }^{36}$-"Vale tanto como rústico, poco cortesano, cuando se dice del hombre o de su razonar y conversar (s.v. grosero), "CAVADOR, el labrador que tiene por ejercicio cavar la tierra, y porque el trabajo los hace fuertes y en todas sus acciones son groseros y poco delicados" (s.v.)-; su trato resulta desapacible ("Los que aquí viven se llaman propiamente villanos y como tienen poco trato con la gente de ciudad, son de su condición muy rústicos y desapacibles, s.v. villa); sus andares son bruscos y su pelo desgreñado ("Los que dan unos pasos atrabancados, arrojando tras el pie todo el cuerpo, son rústicos y tontos", s.v. carcañal; "La cabellera revuelta empelotada, que están los cabellos revueltos unos con otros, se llama greña, quasi creña, a crine, y desgreñada la mujer que trae suelto el cabello y revuelto o enguedejado, o el hombre del campo rústico" (s.v. cabello).

Caracterizan igualmente al aldeano comidas y dolencias singulares ("Migas, cierto guisado rústico de migas o pedazos de pan desmigados", s.v. miga; "Los gañanes de ordinario son muy groseros y grandes comedores de rústicos mantenimientos; y por eso al que come cosas groseras y con exceso y poca policía decimos que come como un gañán”, s.v. gañán; "JUANETES. Son los huesezuelos salidos de los dedos pulgares, así de las manos como de los pies. Arguyen rusticidad y tiénenlos ordinariamente la gente grosera", s.v.juanetes); estos hombres rústicos se identifican por ciertos nombres propios, que se convierten en prototípicos (“y por argüir mal ingenio se llamaron juanetes, de

Cf. a este propósito los trabajos de Salvador $(1988,2006)$.

34 D. Azorín, por ejemplo, enmarca la presencia de información de este tipo en el afán enciclopédico que recorre el Tesoro. "No es extraño, por tanto, que junto al léxico general no marcado, en el Tesoro encontremos, como podemos observar a continuación, voces marcadas por alguna concreta dimensión diasistemática" (Azorín 2000: 122).

No encuentro en la bibliografía, sin embargo, un retrato preciso de la consideración sociolinguística que preside el Tesoro.

35 En el Arte de la Lengua Española Castellana, de 1625, Correas distingue entre uso cortesano, uso poético y uso aldeano (cf. Salvador 1988: 978-983).

36 Grosero es también el hombre chabacano (s.v.)-'hombre grosero, vulgar e impertinente'-, que no se identifica con el rústico, que es grosero en cuanto se encuentra sin desbastar (s.v.): "y hacer que no esté basto y grosero, desbastar un mozo que viene a palacio y se ha criado toda su vida en el aldea". 
Juan, cuando tomamos este nombre por el simple y rústico" ${ }^{37}$, s.v. juanetes). Su forma de hablar -y es este dato el que nos interesa especialmente- es poco pulida, contrapuesta a la cortesana ("Decimos ser necesario desbastar y acepillar a alguno cuando nuevamente empieza a tratar con la gente cortesana, y él es grosero y trata y habla a fuer de su aldea", S.v. acepillar); usan a menudo del refranero popular: "Crespo es apellido, y quedó en proverbio aldeano: «Sentaos Mari Crespa, no os cansedes»»" (s.v. Crespo), y emplean expresiones que les son características -"Irse a novillos, es un término aldeano, cuando un mozo ha salido del lugar con ánimo de ver el mundo y se vuelve dentro de poco tiempo, como hace el que va a comprar novillos a la feria", s.v. novillo.

Aparecen por la obra del toledano términos rústicos, como avechucho (s.v. ave), desenhetrar, ${ }^{38}$ embarbascar, eregir, prohidiar, redro, entre los que incluye también alguna voz de otras lenguas, como sucede en galavardo (s.v.); palabras rústicas (ablentar, s.v.; o quillotro, s.v.) o usadas entre los rústicos: fisco. También se definen algunas voces como vocablos groseros (muévedo, s.v. mover) o palabras groseras y bárbaras $^{39}$ (gomitar y gómito, s.vv.). Otros términos caen bajo la denominación de lenguaje grosero (cacho, s.v.; carapuza, s.v. caperuza), vocablo grosero y aldeano (calvatrueno, s.v.), término aldeano (hogar, s.v., amorío, s.v.), lengua grosera y poco cortesana (alguaquida, s.v.), lenguaje aldeano (hato, s.v.), vocablo bárbaro y aldeano (resquebrajo, s.v. requebrar), término bárbaro y poco usado entre gente cortesana (aburar, s.v.), o palabra bárbara y zafia (he, s.v.). A veces, de acuerdo con el carácter conservador de las hablas rurales, lo rústico, o grosero, y lo antiguo van de la mano: vocablo antiguo rústico (condumio, s.v.; modorra, s.v.), término castellano antiguo y grosero (ende, s.v.), vocablo aldeano, pero muy propio, y usado en la lengua antigua castellana (caridad, s.v.), e incluso se identifican explícitamente: ${ }^{40}$

37 En la versión electrónica del DRAE, se hace referencia también al origen de la denominación juanete: “De Juan, nombre rústico frecuente, pues se atribuía a rústicos ser juanetudo" (DRAE, s.v. juanete).

38 No ofrezco referencia alguna cuando el término en cuestión constituye lema del Tesoro.

39 En la voz bárbaro (s.v.) se lee: “a todos los que hablan con tosquedad y grosería llamamos bárbaros, y a los que son inorantes sin letras, a los de malas costumbres y mal morigerados, a los esquivos que no admiten la comunicación de los demás hombres de razón, que viven sin ella, llevados de sus apetitos, y finalmente los que son despiadados y crueles". De hecho, el adjetivo bárbaro se emplea en el Tesoro, de acuerdo con el uso común en el Siglo de Oro, en varios significados diferentes, aunque emparentados todos ellos. Aparecen otros términos calificados de bárbaros: unos son voces de otras lenguas como carantoña o carátula, maníaco, perqué, zaragüelles, y otros son simplemente voces extrañas al uso común por causas diversas (arcaísmo, neologismo, etc.): abernuncio, abondo, paradijos, arrastradura, aterecerse, despachurrar, gofería, lagunajos, sorbible, mujeriego, compadre, pagadero, simplón, concienzudo, estropezar, sobaco, antaño, palaciego y palanciano, nueso y nuesa, solsobaco, sobarcado, cabelladura, encabelladura. Excepcional es el caso de aína, sobre los que advierte su carácter de "palabras bárbaras" -pienso que ha de interpretarse por antigua, en este caso- pero muy usadas. Corominas señala el uso de aína hasta el siglo XVII ("Quevedo la ridiculiza en Cuento de Cuentos, DCECH, s.v.); oxte, sin embargo, resulta de uso común en los siglos de Oro.

En algunos casos, no parecen claros los límites entre antiguo, rústico y bárbaro, pues parece que el carácter bárbaro de algunas voces viene provocado por su antigüedad. Por tanto, en estas páginas únicamente se considera bárbaro como marca diastrática en el caso de que exista coordinación con otro término que puede entenderse más claramente en este sentido.

40 Covarrubias muestra a lo largo de toda la obra una especial inclinación y reverencia hacia las lenguas clásicas (griego y latín) (cf. Seco 2003a), que se deja ver en afirmaciones de este tipo: "Yo te ruego, joh pío letor!, no tomes pesadumbre, ni te dé fastidio que le repita en este lugar, porque me excuse de decir con palabras profanas y groseras, lo que la Iglesia nos canta con tanta melodía y dulzura" (s.v. gallo). Por esta razón, y por las concomitancias que la lengua antigua pueda presentar en algunos de sus usos con el habla rústica -más conservadora (cf. nota anterior)-, no resulta extraño que cualquier vocablo antiguo sea, por definición, rústico o grosero. 
"La lengua antigua española debió ser difícil y áspera de pronunciar a los forasteros y por esta razón se debe estimar, siendo lengua varonil”, s.v. lengua.

Por otra parte, Covarrubias salva algunos términos rústicos de rasgos que les son intrínsecos como su bajo origen (pescudar -“Término rústico, pero de buen origen”, s.v.) o su impropiedad ("Carillo, vocablo aldeano, pero muy propio, y usado en la lengua antigua castellana", s.v.; "El vocablo marrar es bárbaro y no usado entre gente cortesana, pero muy propio", s.v. marrar).

En algunas voces se contrapone explícitamente el término más neutro, o quizá culto, con el más grosero: ${ }^{41}$ aborrecer/ aburrir y aburrido ${ }^{42}$ (s.v. aborrecer), calavera/ calaverna (s.v. calavera), copete de los cabellos/mechón de cabellos (s.v. carámbano), hierba gatera/gatuña (s.v. gata y gato); regalillo/manguilla (s.v. manga), lienzo/paño de narices (s.v. fazoleto), rostro/carátula (s.v. máscara), hacer aguas/orinar y aguas/ orines (s.v. orinar), o se desprecian ciertas voces por impropias de gente cortesana (atusar, s.v.).

Por contraposición, el cortesano (s.v. corte) es "el que sigue la corte, sirviendo al rey; y porque se presume que los tales son muy discretos y avisados, llamamos cortesanos a los que tienen bueno y hidalgo término y honrado trato", de gustos culinarios refinados ("AJo. [...] No es comida para gente cortesana", s.v.).

Las voces que usan los cortesanos se marcan con sintagmas del tipo término ciudadano y cortesano -policía, s.v.-, con referencia directa al hablante -fazoleto, orinar- o con la expresión "en término cortesano", que Covarrubias refiere a acepciones sociolingüísticamente restringidas; de este modo sucede en afear -"En término cortesano, afear sinifica representar a alguno cuán malo y detestable sea algún pecado o delito que haya cometido, para que se confunda y enmiende" (s.v.)-, fineza -"Fineza, significa algunas veces agudeza, otras perfeción de la cosa, y en término cortesano cierta galantería y hecho de hombre de valor y de honrado término", s.v. fin.

Por fin, Covarrubias señala en su Tesoro usos traslaticios, que constituyen las que la lexicografía denomina acepciones figuradas o secundarias ("Cavador, el labrador que tiene por ejercicio cavar la tierra, y porque el trabajo los hace fuertes y en todas sus acciones son groseros y poco delicados, solemos decir de algún ciudadano robusto, que es como un cavador", s.v. cava), en términos susceptibles de emplearse de modo insultante ("Porro, decimos al necio por no ser nada agudo, sino grosero, como el cabo de la porra; esa mesma semejanza tiene el majadero y badajo", s.v. porra), sin que existan en estos casos alusiones al carácter injurioso de los términos.

Cabe mencionar, por último, una referencia metalingüística al uso de palabras soeces, o cazurras, como el autor las denomina según la tradición medieval de las Partidas, concomitantes a veces con las injuriosas, que incluso los villanos evitan:

De manera que palabras cazurras son las que no se pueden pronunciar sin vergüenza del que las dice y del que las oye, como nombrar el miembro genital de uno y otro sexo y otros vocablos semejantes, que los villanos suelen hacer la salva por este término: «Hablando con perdón de su merced y de sus barbas honradas» (s.v. cazurras).

${ }^{41}$ Señalo en cursiva el término marcado como rústico o grosero.

42 En los siglos XVI y XVII aborrecer valía por 'aburrir, fastidiar’ (DCECH, s.v. aburrir). 
En resumen, Covarrubias ofrece en su obra una descripción de los distintos tipos sociales -rústicos, aldeanos o bárbaros frente a cortesanos- y de los usos lingüísticos que los caracterizan en una escala según la cual el culto y cortesano representa el ideal social y lingüístico opuesto al rústico y aldeano, de costumbres denostables. ${ }^{43}$ Sin embargo, en esta caracterización no se encuentra indicación alguna sobre una proclividad especial hacia el vocabulario o las expresiones injuriosas, de igual manera que con anterioridad hemos comprobado que los términos marcados como afrentosos no se atribuyen a grupo social o individuo determinado. Del mismo modo, al uso de los españoles en general, sin restricciones de nivel, se refiere Álvarez Tejedor en su revisión en las gramáticas del XVI de las alusiones a la costumbre de insultar o motejar: "Pero si tan ceremoniosos son los españoles hablando de su lengua no son menos finos a la hora de motejarse o insultarse: los motes más usuales son loco, o judío (que toca al honor), o moro, o necio" (Álvarez Tejedor 2006: 450). ${ }^{44}$

Esta visión del insulto como uso lingüístico nivelador, que no entiende de distinciones sociales en la figura del emisor, coincide con la que reproducen los usos literarios. La comedia y la tragedia del Siglo de Oro y anterior, esto es, las obras dialogadas, colocan insultos (Arellano 2013; Duarte 2013; Herrero 2013 y Oteiza 2013) en boca de señores y graciosos, de hombres y de mujeres, si bien la licitud de uso viene regulada por la condición social de ofensor y ofendido: está permitido el insulto de un superior a un inferior o entre iguales de bajo nivel -habitualmente, los graciosos (Cf. a este propósito Oteiza 2013: 184-187)-; el inferior injuria al superior siempre que este no lo escuche. ${ }^{45}$

\section{Covarrubias y la injuria en el Siglo de Oro}

La injuria en el Tesoro de Sebastián de Covarrubias se dibuja principalmente como acción públicamente ofensiva contra la fama el otro (§2.1) que, solo en ocasiones, puede tomar carácter verbal (§2.2). Las acciones afrentosas, a las que se añaden gestos y signos agraviantes, ocupan en esta obra un espacio semejante al que representaban en la sociedad de aquel momento, absolutamente preocupada por los valores del honor y de la honra y por todo aquello que afectara a la fama y consideración del individuo.

En este escenario social, en el que los textos de ficción y realidad ofrecen un uso amplio y numeroso de la injuria a través de la palabra, Covarrubias se limita a presentar unos pocos, escasísimos, ${ }^{46}$ términos y expresiones que reciben esta valoración por parte del autor: al rollo de Écija, que le estire, bigardo, cesto, fulanillo, furcifer, gafo, ladrón, mala hembra, sois un figón, zutanillo, al lado de otras tres -

43 No faltan en el Tesoro referencias al lenguaje de germanía, que se define como propio de "rufianes, ladrones y vagamundos" (s.vv. cicatero, cherinola y jacarandina). También alusiones a palabras o expresiones germanescas en cantar (cantar el potro), cicatera, coime, xaque. En lilao, s.v., Covarrubias habla de un "término vulgarísimo, apicarado y casi de la germanía".

44 Este autor revisa las gramáticas del Anónimo de Lovaina, la de Juan de Miranda, la de Villalón, la Gramática de la lengua vulgar de España, la de Antonio de Corro y la de William Stepney.

45 Esta premisa anula, en rigor, el efecto ilocutivo y, por tanto, el acto injurioso; sin embargo, el efecto infamante persiste porque existe siempre un "oidor" de la imprecación, que podrá ser otro personaje o el público.

46 Resulta evidente la mínima representación porcentual que representan estas voces en relación con el total, por mucho que este varíe según el recuento de los distintos estudios, de las incluidas -lematizadas o no- en el Tesoro. 
cojo, destripaterrones, tuerto- cuya intención escarnecedora las vuelve injuriosas. Entre estos términos, gafo y ladrón son las sancionadas por la ley en su uso recto, mientras que el resto tiene su origen en procesos metafóricos que desembocan en desviaciones significativas; las que designan defectos físicos o costumbres poco recomendables (cf. §§3.1 y 3.2).

En comparación con las menciones a la afrenta, resultan poco representativas, pues, en el conjunto de la obra las voces que Covarrubias califica de injuriosas, sin que pueda atisbarse sistematicidad alguna en la selección, que encuentra motivos de naturaleza diversa: la tradición jurídica (cornudo, ladrón, gafo, sois un figón 'sodomita'), que apunta hacia valores de trascendencia social y castigo legal y pecuniario; la condición personal del autor, que provoca la vehemencia contra determinados usos (bigardo) -quizá haya de incluirse aquí mala hembra y el respeto debido hacia las mujeres en su condición de madres ${ }^{47}$ - y, por fin, la información enciclopédica del Tesoro, que une expresiones de desprecio (fulanillo, zutanillo) y otras que marcan grupos sociales determinados (al rollo...), e, incluso, la conmiseración hacia los "pobres lastimados" (s.v. escarnecer) por limitaciones que constituyen tradicionalmente objeto de burla y mofa (tuerto, cojo).

Es cierto, por tanto, que la selección de voces que se tachan de injuriosas no escapa a la asistematicidad, entendida siempre en el contexto lexicográfico del Tesoro, que reiteradamente se ha atribuido a la obra de Covarrubias. No deben perderse de vista, sin embargo, algunos detalles, entiendo que fundamentales, a la hora de buscar un criterio para la inserción o ausencia de esta clase de voces. No parece ser fruto de la casualidad la referencia nula al uso injurioso de vocablos ampliamente extendidos en la sociedad áurea del tipo puta, bellaco, borracho, judío, loco, traidor, que se muestran como términos de frecuencia elevada, aunque en acepciones que se han desemantizado por la pérdida de algunos de sus semas constitutivos, derivando en una relación de hiponimia entre ellos hacia el hiperónimo malo o mala persona. Frente al matiz de conmiseración al que me refería más arriba, que vuelve injustas tales injurias (tuerto, cojo ${ }^{48}$ ), cabría pensar en el sentir del autor en cierta justificación en la emisión de estas otras, cuyo uso ofensivo, en consecuencia, ni siquiera se anota, en casos especialmente presentes en la sociedad como el de judío. ${ }^{49}$

Por otra parte, resulta evidente, y así se expresa con la mayor explicitud en la voz cazurras (cf. supra), que Covarrubias huye de las palabras groseras, que incluso ni los villanos pronuncian (s.v. cazurras), lo que encaja con el modelo de lengua culta, o mejor propia de cultivados, que recoge en su obra.

Por su lado, Autoridades (cf. §3.3) supone un avance escasamente significativo sobre Covarrubias, ${ }^{50}$ más en el señalamiento de acepciones secundarias que en la marcación de uso de los términos empleados como vituperosos. En este caso, la selección académica refleja el mal trato a los judíos (judío, judihuelo y perro) o a

\footnotetext{
47 Recuérdese (§3.3) la justificación del autor en este caso: "y en fin nacimos de hembras, y sea hi de mala el que dixere de proposito mal dellas" (s.v. hembra).

48 También en gafo se manifiesta el espíritu compasivo y la injusticia del agravio (s.v. gafo).

49 Para el antijudaísmo de Covarrubias a través del Tesoro, cf. Reyre (1994). 
aquellos de diversa procedencia (gabacho); evita por principio las palabras soeces. ${ }^{51}$ La lexicografía española posterior, hasta fecha recentísima, seguirá manteniendo esta tendencia, a saber, la escasa marcación como injuriosas de las voces que la lengua presenta codificadas en este uso, en gran medida por su concomitancia con las palabras soeces y juramentos que la norma culta desprecia; no en vano incluso la lexicografía actual ha considerado las voces insultantes propias del caló, del argot y de la germanía (cf. Colín 2003: 420).

Por último, se comprueba que en el caso de las voces marcadas como injuriosas en el Tesoro, y también en Autoridades, no se plantea la condición social del emisor (cf. §4), porque puede ser esta cualquiera de las posibles, ${ }^{52}$ la clave del uso radica en la relación jerárquica o de solidaridad que exista entre los interlocutores. Como decía el propio Covarrubias (cf. §2), “Decirle a uno en sus barbas algún denuesto es haberle perdido el respeto, quien debía tenérsele y reverenciarle" (s.v. barba).

En resumen, el Tesoro inaugura en el tratamiento lexicográfico del insulto una línea de actuación que perpetuarán las obras posteriores en cuanto a la ausencia de lematización de palabras vedadas y codificadas como injurias, tanto en la lengua propia de rústicos y gente grosera como en la cortesana. Se trata, sencillamente, de términos que no deben tener cabida en el acervo léxico de una lengua noble; de ahí su consideración única en obras especializadas, de lenguajes marginales, que solo en los últimos años de nuestro presente encuentran lugar en los diccionarios generales.

\section{OBRAS CITADAS}

Álvarez Tejedor, Antonio. 2006. “Cómo se hablaba en el español del siglo XVI a la luz de las gramáticas?”. Gómez Asencio, José J., dir., El castellano y su codificación gramatical. De 1492 (Nebrija) a 1611 (John Sanford). Volumen I. Burgos: Instituto Castellano y Leonés de la Lengua/ Junta de Castilla y León. 435-453.

Arellano, Ignacio. 2013. "Injurian los poetas. Algunos usos, funciones y perspectivas del insulto en el Siglo de Oro". Pérez-Salazar, Carmela, Cristina Tabernero y Jesús M. Usunáriz, eds., Los poderes de la palabra. El improperio en la cultura hispánica del Siglo de Oro. New York, Washington D.C./Baltimore, Bern, Frankfurt, Berlin, Brussels, Viena, Oxford: Peter Lang. 7-25.

Austin, John. 1994. How to Do Things with Words. Oxford: Oxford University Press.

Azorín, Dolores. 2000. Los diccionarios del español en su perspectiva histórica. Alicante: Publicaciones de la Universidad de Alicante.

Castillo, Mónica. 2004. "De verbo vedado: consideraciones lingüísticas sobre la agresión verbal y su expresión en castellano medieval". Cahiers de linguistique et de civilisation hispaniques médiévales 27: 23-35.

Colín, Marisela. 2003. El insulto: estudio pragmático-textual y representación lexicográfica. Tesis de doctorado. Disponible en <http://www.tdr.cesca.es/TESIS_UPF/AVAILABLE/ TDX-1230103-114332//tmcr1de1.pdf $>$.

Corominas, Joan, con la colaboración de José Antonio Pascual. 1987-1991. Diccionario críti-

Señala F. Lázaro a este respecto: "Con los vocablos sucios se harán tres grupos; mantendrán su franquía las voces "comunísimas" y las que se limpian al entrar en ciertos sintagmas, como culo de pepino; pero la escoba será implacable para todas las malolientes invenciones de la «gente soez »". (Lázaro 1980: 111). Cf. también Garriga (1994).

52 El mismo Covarrubias, en una referencia que he reiterado con diversos propósitos en estas páginas, escribe, aunque eufemísticamente: "y sea hi de mala el que dixere de proposito mal dellas" (s.v. hembra). 
co-etimológico castellano e hispánico. 6 vols. Madrid: Gredos.

Covarrubias, Sebastián de. 2006. Tesoro de la lengua castellana o española. Eds. Ignacio Arellano y Rafael Zafra. Madrid: Iberoamericana.

García-Medall, Joaquín. 2008. "El insulto desde la pragmática intercultural”, en Álvarez Tejedor, Antonio et al., coords., Lengua viva. Estudios ofrecidos a César Hernández Alonso. Valladolid: Universidad de Valladolid. 667-680.

Garriga, Cecilio. 1997. "Las marcas de uso en los diccionarios del español”. Revista de Investigación Lingüística 1: 75-110.

1994. "La marca de vulgar en el DRAE de Autoridades a 1992". Sintagma 6: 5-13.

Gemmingen, Barbara von. 1992. "Le Tesoro de la lengua castellana, o española de Sebastián de Covarrubias (1611) et la naissance du dictionnaire monolingue en Espagne", en Lorenzo, Ramón, ed., Actas do XIX Congreso Internacional de Lingüística e Filoloxía Románicas. La Coruña: Fund. Pedro Barrié de la Maza. 25-33.

Haverkate, Henk. 1994. La cortesía verbal. Estudio pragmalingüístico. Madrid: Gredos.

Herrero Ruiz de Loizaga, Francisco Javier. 2007. "El insulto en la comedia celestinesca". Cortés, Luis, ed., Discurso y oralidad: homenaje al profesor José Jesús de Bustos Tovar. 1. 349-365.

. 2013. "El insulto en obras dialogadas de los siglos XVI y XVII". Pérez-Salazar, Carmela, Cristina Tabernero y Jesús M. Usunáriz, eds. 2013. Los poderes de la palabra. El improperio en la cultura hispánica del Siglo de Oro. New York, Washington D.C./ Baltimore, Bern, Frankfurt, Berlin, Brussels, Viena, Oxford: Peter Lang. 149-173.

Lázaro Carreter, Fernando. 1980. "El primer diccionario de la Academia". Estudios de Lingüística. Barcelona: Crítica. 83-148.

López Martín, José Manuel. 2013. "El insulto como estrategia de descortesía extrema en un nuevo formato audiovisual: la radio televisada". Fuentes, Catalina, coord., (Des)cortesía para el espectáculo: estudios de pragmática variacionista. Madrid: Arco/Libros. 211231.

Madero, Marta. 1992. Manos violentas, palabras vedadas. La injuria en Castilla y León (siglos XIII-XV). Madrid: Taurus.

Nueva Recopilación. Segunda Parte de las leyes del Reyno. Libro quinto. 1982. Valladolid: Editorial Lex-Nova.

Oteiza, Blanca. 2013. "Ofensas en el teatro de Tirso de Molina”. Pérez-Salazar, Carmela, Cristina Tabernero y Jesús M. Usunáriz, eds. 2013. Los poderes de la palabra. El improperio en la cultura hispánica del Siglo de Oro. New York, Washington D.C./Baltimore, Bern, Frankfurt, Berlin, Brussels, Viena, Oxford: Peter Lang. 175-189.

Pérez-Salazar, Carmela, Cristina Tabernero y Jesús M. Usunáriz, eds. 2013. Los poderes de la palabra. El improperio en la cultura hispánica del Siglo de Oro. New York, Washington D.C./Baltimore, Bern, Frankfurt, Berlin, Brussels, Viena, Oxford: Peter Lang.

Real Academia Española. 2001. Nuevo Tesoro Lexicográfico de la lengua española. Ed. en DVD. Madrid: Espasa.

. Corpus diacrónico del español. Banco de datos [en línea]. Disponible en: http://www. rae.es.

Reyre, Dominique. 1994. "La voz judío en el Tesoro de la Lengua Castellana o Española de Sebastián de Covarrubias y en su Suplemento". Criticón 61: 81-94.

2006. "Prólogo segundo. Las llaves del Tesoro de Covarrubias". Covarrubias, Sebastián de. 2006. Tesoro de la lengua castellana o española. Ignacio Arellano y Rafael Zafra, Eds. Madrid: Iberoamericana. XLV-LXVI.

Ridruejo, Emilio. 2000. “La formulación de componentes 'pragmáticos' en el Tesoro de Covarrubias”. Bagola, Béatrice, ed., La lingüística española en la época de los descubrimientos. Hamburg: Buske. 135-148.

Salvador, Antonio. 1988. "Niveles sociolingüísticos en Gonzalo de Correas”. Ariza, Manuel, 
Antonio Salvador y Antonio Viudas, eds. Actas del I Congreso internacional de Historia de la lengua española. vol I. Madrid: Arco/Libros. 977-993.

. 2006. "Los tratadistas del siglo de oro como fuente para el análisis de historia de la lengua”. Bustos Tovar, José Jesús y José Luis Girón Alconchel, eds., Actas del VI congreso internacional de Historia de la lengua española. vol. 1. Madrid, 29 de septiembre-3 de octubre de 2003. Madrid: Arco/Libros. 159-183.

Seco, Manuel. 2003a. "Un lexicográfo de la generación de Cervantes (Notas sobre el Tesoro de Covarrubias)". Estudios de lexicografía del español. $2^{\mathrm{a}}$ ed. aum. Madrid: Gredos. 185-201.

2003b. "Covarrubias en la Academia". Estudios de lexicografía del español. $2^{\mathrm{a}}$ ed. aum. Madrid: Gredos. 222-236.

Segura, Félix. 2005. "Verba vituperosa: El papel de la injuria en la sociedad bajomedieval". García Bourrelier, Rocío y Jesús María Usunáriz. Eds., Aportaciones a la historia social del lenguaje: España, siglos XIV-XVIII. Madrid-Frankfurt: Iberoamericana-Vervuert. 149-195.

Tabernero, Cristina. 2010. "Injurias, maldiciones y juramentos en la lengua española del siglo XVII”. Revista de Lexicografía 16: 101-122.

2012. "Estudio de algunas voces injuriosas del español clásico". Nomdedeu, Antoni, Esther Forgas y Maria Bargalló, eds. Avances de lexicografía hispánica (I). Tarragona: Universitat Rovira i Virgili. 495-508.

2013. "Léxico injurioso y tipos de discurso en el Siglo de Oro". Pérez-Salazar, Carmela, Cristina Tabernero y Jesús M. Usunáriz, eds. 2013. Los poderes de la palabra. El improperio en la cultura hispánica del Siglo de Oro. New York, Washington D.C./ Baltimore, Bern, Frankfurt, Berlin, Brussels, Viena, Oxford. Peter Lang: 257-275.

Usunáriz, Jesús María. 2013. "Limpios de mala raza: insultos contra los judeoconversos en la Navarra del siglo XVI”. Pérez-Salazar, Carmela, Cristina Tabernero y Jesús M. Usunáriz, eds., Los poderes de la palabra. El improperio en la cultura hispánica del Siglo de Oro. New York, Washington D.C./Baltimore, Bern, Frankfurt, Berlin, Brussels, Viena, Oxford: Peter Lang. 277-297. 
